Vol. 2, No. 2, 2021

ISSN (ONLINE) 2597-0593

DOI 10.7146/njlis.v2i2.125238

(c) CC BY-NC-ND 4.0

Joacim Hansson, Professor, Department of Cultural Sciences, Linnaeus University, Sweden, joacim.hansson@Inu.se

Koraljka Golub, Professor, Department of Cultural Sciences, Linnaeus University, Sweden, koraljka.golub@Inu.se

Jukka Tyrkkö, Professor, Department of Languages, Linnaeus University, Sweden,

jukka.tyrkko@Inu.se

Ida Ahlström, Librarian, Linnaeus University Library, Sweden, ida.ahlstrom@Inu.se

\title{
Publication practices in the Humanities
}

\author{
An in-depth case study of a Swedish Arts \\ and Humanities Faculty 2010-2018
}

\begin{abstract}
This paper is a case study of research publication practices at the Faculty of Arts and Humanities at Linnaeus University, a young, mid-sized university in the south-east of Sweden. Research output was measured from publications in the local institutional repository following the guidelines of local research policy as defined in university documentation. The data collection comprised 3,316 metadata records of publications self-registered by authors affiliated with the faculty during the period of 20102018. A statistical analysis of research output was conducted, focusing on preferred publication types, disciplinary specificity, level of co-authorship, and the language of the publication as registered in the local repository. The analysis focused on two main research questions: 1) how do the local research practices stand in relation to traditional publication patterns in the humanities? 2) how do the observed publication patterns relate to local university policy on publication and research evaluation? The empirical results suggest a limited correlation between publication practices and research incentives from university management, a finding that is corroborated by previous research on the scholarly character of the humanities and university policies. Overall, traditional humanities publication patterns were largely maintained throughout the period under investigation.
\end{abstract}

Keywords: humanities, research evaluation, publication practices, scientific communication, bibliometrics, research policy 


\section{Introduction and purpose}

The recent developments of the humanities in the contemporary environment of digital scholarship in higher educational institutions should perhaps not be seen so much as a paradigmatic shift, but rather as a process of gradual transformation and adaptation to ever-evolving new methodological options, which may increase opportunities to ask new questions, answer existing ones more rapidly, and gain access to new and more extensive source materials. While these developments are taking place, the well-established characteristics of research practices and publication patterns continue to hold their ground in many disciplines, as seen, for example, in the relative ambiguity between information, data and documents, and in the multitude of different audiences for research output, mirrored in a variety of publication forms, both physical and digital (Borgman, 2007; Kennerly et al., 2021). In parallel to the research practices of individual disciplines, universities have developed performance-based funding systems that in many cases appear to encourage uniformity in their criteria for output measurement and quality assessment. This uniformity is especially salient in the way these criteria, in one way or another, relate to and draw from combinations of bibliometric data. The ways in which such performance-based systems are used for management and funding are complex, as are the relations between policymaking and research quality (Aagaard, 2015; Carlsson et al., 2014).

Bibliometric measurements traditionally reflect the publication practices of the natural sciences, prioritizing international peer-reviewed journals and conference proceedings in English, indexed through bibliographic services such as Web of Science (WoS) and Scopus. By contrast, less emphasis is given to alternative publication forms such as monographs, edited volumes, and essays, all of which are more prevalent in the humanities. Likewise, the practice of publishing in languages other than English, which is also significantly more widespread in the humanities, is discouraged by bibliometric measurements. Consequently, in order to make bibliometric assessment tools take the publication practices of the humanities into account, some adjustments and compensations would be necessary. Although the complex relation between bibliometrics and university research assessment are well known, there are few studies on how this takes shape at the local level; more commonly, studies focus on the use of institutional repositories that often serve as the basis for research assessment (for examples of the latter, please see Narayan et al. (2018), Guns et al. (2019), and Sïle and Vanderstraeten (2019)).

The purpose of this study is to contribute to this research through a case study of the research practices in the Faculty of Arts and Humanities of Linnaeus University, a young, regional Swedish university. By analysing the complete scholarly output of its humanities researchers during the period 2010-2018, conclusions will be drawn about 1) research practices in relation to traditional publication patterns in, and assumptions of, the humanities, and 2) how these practices relate to local university policy on publication and research evaluation. The main research question concerns the relation between policy initiatives and publication practices, based on the analysis of the local publication pattern as to:

- $\quad$ Preferred publication types

- Disciplinary specificity

- $\quad$ Level of co-authorship

- Preferred publication language

These four aspects were chosen based on prior research, which has shown them to be distinguishing characteristics of humanities research, both in comparison to other branches of the sciences, and in relation to general criteria of evaluation. Relating the results of the data analysis to the overall 
objectives and policy formulations of the Faculty and the University, conclusions will be drawn on whether a positive correlation can be observed between university policy and publication practices, or whether publication practices are more reflective of disciplinary traditions and the preferences of individual researchers.

Concentrating the discussion to one local environment helps bring the generally well-known structures of publishing into a context where traditional practices are challenged not only by technological and methodological developments, but also by the concrete goals of governance and university management. Additionally, and importantly, this focus provides insights into the actual working conditions of humanities scholars. It should be noted that this study does not have an evaluative perspective. It is basically exploratory, and the references to bibliometric and research evaluation perspectives are used as a tool for interpreting the data in an institutional context, which also makes it possible to discuss observations made at the local level in relation to issues at a more general level.

The paper is structured as follows: section 2 (Background) gives an overview of previous research on the differences between the sciences and humanities both historically and today, particularly in light of the development of bibliometrics as a tool for research evaluation. This section also introduces Linnaeus University as the site of the case study. Section 3 (Data collection and method of analysis) provides a brief overview of the methodology and research design. The results of the empirical part of the study using extracted bibliographical data are presented in section 4 (Results). Section 5 (Concluding remarks) relates the findings to the more relevant practices discussed in section 2 and raises questions about the impact of local managerial practices and incentives on publication practices.

\section{Background}

This section begins with a contextual overview of the humanities in relation to the natural sciences as seen through discussions of publication practices and bibliometrics. This is followed by a brief description of Linnaeus university and its research policy, including policies on publication practices in force during the studied period. The section concludes with a description of the bibliometric model used at the university.

\subsection{The humanities from 1960s to today's age of digital scholarship}

There has been a distinct division between the sciences and the humanities since a more technologydriven understanding of scientific progress took hold in the aftermath of World War II, perhaps most famously formulated by C. P. Snow in his contentious Rede lecture The Two Cultures (Snow 1959). In the lecture, Snow draws a picture of the humanities as a broad and diverse field based on interpretative ideals of knowledge and a propinquity to artistic expressions that are hard to define by scientific measures or established quality assessment criteria, on which the natural sciences thrive. This picture was later embodied by Derek de Solla Price in his early bibliometric efforts - at the time the field was still called analytical bibliography - through several publications that distinguish the 'hard' sciences from the 'soft' based on their citation practices (de Solla Price 1963 and 1965). The hard vs. soft distinction reflects Snow's two cultures, ensuing from the premise that it is possible to quantify both research results and bibliographic output in individual disciplines, with the humanities firmly situated on the soft, less quantifiable side of the spectrum.

There are of course good reasons to question such simplistic divisions, not least as the past fifty years have witnessed a significant change in the dynamics between academic disciplines and scholarly traditions both through technology and ideals promoting cross-disciplinary research endeavours that 
transgress the traditional borderlines drawn up by both Snow and de Solla Price. In particular, the current developments in digital scholarship challenge the assumed division into two cultures. However, despite numerous efforts to influence and counteract these divisions, disciplinary traditions of established publication practices run deep. The breakdown of publication types (articles, books etc.) in the humanities does not seem to have changed significantly, while more substantial changes can be seen in the choice of publication languages as well as the scientific level (peer review, other) of publications. Recent studies show that humanities publications written in national languages are decreasing in favour of the English language, while publishing in peer reviewed publications is on the rise. At one Swedish university the general breakdown of publication types in the humanities did not change during the period 2006-2013, while in Flemish universities the amount of humanities journal articles was declining slightly in favour of book publications during the period 2000-2014 (Hammarfelt \& de Rijcke, 2015; Guns et al., 2019). At another Swedish university, in a study of educational sciences publications, a shift towards a higher share of journal articles could be seen during the period 2005-2014, while the share of reports had decreased (Sïle \& Vanderstraeten, 2019). The authors of the latter three studies note that these changes are in line with the national and local allocation models emphasising the importance of international and peer reviewed journal articles. They also conclude that the introduction of such models cannot be considered as a singular cause of the changes, and that the influence of, for example, open access, competition in academia, and academic age of authors are hard to separate from each other. Sile and Vanderstraeten (2019) note that the changes were present before the introduction of the models. In addition, Hammarfelt and de Rijcke (2015) identify a discrepancy between what publication types the humanities researchers consider the most important and what publication types they actually favour. Book chapters are not considered by researchers to be as important as journal articles, but they are still the most frequent type of publication in the repository, alongside journal articles. Furthermore, the study concludes that even though the humanities researchers are aware of the external pressure from bibliometric evaluations, this pressure has had little effect on preferred types of publication.

Although the present study will not focus on the development of digital humanities as such, we consider this particular area worth a special mention as it permeates several strains of international scholarly discourse relevant to the dataset. Digital humanities challenge the traditional divide between the humanities and the sciences in several areas such as language use and publication choices. Tang et al. (2017) analyse the intellectual cohesion in digital humanities during the period 1989-2014, using bibliographic coupling, co-author analysis, and co-citation analysis of 2,115 articles in six peer-reviewed digital humanities journals; only one of the journals, Literary and Linguistic Computing, was indexed by Scopus at the time of data collection. The results showed that, even though an emerging common-knowledge base can be identified over time, digital humanities research maintains several traditional characteristics of the humanities, such as low degrees of coauthorship often realised in the form of bibliometric "small world" clusters, a tendency in favour of localised geographical settings, and the use of national languages. It is worth keeping such results and discussions in mind as they mirror well-known problems of contemporary university and research funding development, not least those that create incentives for team research and cross-disciplinary research environments in the humanities in general (Siemens, 2009; Siemens et al., 2011; Burroughs, 2017) as well in interdisciplinary fields such as library and information science (Budd \& Dumas, 2014).

\subsection{Humanities and bibliometric research evaluation}

In an analysis of how social structures and publication practices in the humanities have been studied in bibliometric studies since the early 1960's, Franssen and Wouters (2019) distinguish two periods. The first extends to the mid 1980's and uses bibliometric tools to analyse the social structures of disciplines, thus relating to a paradigm within the subfield of sociology of science, while the second, 
from the mid 1980's onward, places bibliometric research in relation to science policy and research evaluation. This second phase, in part, explains the emergence and use of institutional repositories of research assessment at the local level.

According to Hammarfelt (2016), this development can be seen as a sign of a growing maturity in the use of bibliometric tools. However, in a call for more humanities-friendly assessment practices in WoS and Scopus, Hammarfelt has shown alarming insufficiency in subject indexing of humanities publications which these services ought to provide both for evaluation as well as for searching (2016). As evaluation systems take into consideration broader metadata than just bibliographic records, the relation between indexing and bibliographic evaluation becomes more complex. Several initiatives have been launched, and new methods developed, in order to overcome the problem concerning bibliometrics and subject indexing of humanities research, not least as demands on publication-based assessment for research funding and ranking have increased. Such initiatives include the European Reference Index of the Humanities (Bunia, 2016), developed within the framework of the European Science Foundation, which works to "enhance the global visibility of high-quality research in the humanities and social sciences across Europe, and to facilitate access to research journals published in all European languages" (European Science Foundation, 2014). Another initiative is the Norwegian model for weighing publications based on the production of research output at Norwegian universities (Ahlgren et al., 2012; Schneider, 2009).

Assessment-related issues are getting increasingly complex due to a growing number of stakeholders interested in, and depending on, evaluation criteria and quality assessment: the scholars, educators, funding bodies, university administrators, and political entities. This requires not only adaptation from the scholars, but also the development of refined tools throughout the system of scholarly communication. This has proven difficult to achieve, not least in relation to the humanities which, in a broad overview of recent developments in the field by De Silva and Vance (2017), are not even mentioned. Instead, they are submerged in the sciences, thus ignoring apparent differences across the spectrum of disciplines, whether within the humanities or the social sciences.

With all these results and discussions in mind, it is both legitimate and important to study publication practices in local academic environments. Complex processes run in parallel; traditional patterns and new demands, and they all converge locally. This is what we now will turn our attention to.

\subsection{Linnaeus University as case}

Linnaeus University is a regional two-campus university in the south-east of Sweden, founded in 2010 through a merger of University College of Kalmar and Växjö University. As of February 2020, the university has about 33,000 students and 817 researchers in various faculty positions. It is structured into five faculties, of which the Faculty of Arts and Humanities is one. The University has a strong focus on collaboration with the surrounding society and an explicit aim to provide knowledge production in relation to local and regional economic development. In line with national research policy objectives, cross-disciplinary research is strongly encouraged through organizational and economic incentives, and such initiatives were increasingly visible during the studied period in a growing number of centres that cross faculty lines. The years covered in this study are thus signified by change and development, both in terms of new managerial ideals and in the development of new policies including those concerned with publishing. Throughout this period, the University has maintained a certain traditional focus on social sciences and the humanities, inherited from the priorities of, primarily, Växjö University. 
During the time period in question, the Faculty of Arts and Humanities had 207 active researchers in various faculty positions, and consisted of seven departments (with the number of researchers in parentheses):

- Department of Cultural Sciences (50),

- Department of Design (27),

- Department of Film and Literature (33),

- Department of Languages (31),

- Department of Media and Journalism (13),

- Department of Music and Art (28),

- $\quad$ Department of Swedish (25).

Between these departments, 31 fields of study are represented in educational programs and research initiatives: archaeology; art science; comparative literature education; comparative literature; creative writing; cultural sociology; digital humanities (introduced in 2019); English education; English literature; English; film studies; French linguistics; French literature; German education; German literature; German history education; history; human geography; library and information science; linguistics; music education; music; musicology; Spanish literature; Spanish; study of religions; Swedish as a second language; Swedish didactics; Swedish; teaching and learning in French as a second language; visual culture.

Several cross-disciplinary initiatives were hosted by the Faculty of Arts and Humanities during the period, such as Linnaeus University Centre for Concurrences in Colonial and Postcolonial Studies, Linnaeus University Centre for Intermedial and Multimodal Studies, and Linnaeus University ilnstitute. These centres assemble scholars not just from within the faculty, but from a broad spectrum of academia, industry, and the cultural heritage sector.

In order to fully understand the empirical data, it is necessary to mention existing local policies at the University, regarding 1) research strategy, and 2) publication policy. Even though this study does not concern research evaluation as such, it is useful to have an understanding of the value and actual impact of policy initiatives and guidelines on actual publication output, not least as we are dealing here with a very young university that during the period of study formulated new policies to fit its current requirements in terms of new divisions of labour and constructing faculty and departmental structures that were not there before 2010. The subsequent policy review is based on internal white papers and published guidelines, see Appendix 1.

\subsubsection{Research policy at the Faculty of Arts and Humanities}

During the years 2010-2018, the Faculty of Arts and Humanities had no explicit research policy. Instead, a number of internal documents were produced in support of a) a general research strategy of the University, and b) a general strategy for all activities of the faculty, thus including for instance issues concerning research education.

The contribution of the faculty to the development of a general research strategy for the University consisted of a number of aspects, such as promotion of individual scholarly excellence, significance of cross-disciplinary research environments, maintaining international networks, and societal relevance. Of these, the development of cross-disciplinary research environments and the emphasis on societal relevance, defined by the University as "meeting societal challenges", are particularly challenging to many humanities scholars. A summary report of a survey-based self-evaluation of scholarly activity at the Faculty of Arts and Humanities was produced in 2016 (LNU/FKH1), explaining 
how the faculty meets the requirements and demand of the overall University strategy, A Journey into the Future: Vision and Strategy 2015-2020 (translated title LNU2). In the report, three examples are highlighted to prove that challenging areas are actively met: Anthropocene: Transdisciplinary Perspectives on Sustainable Development; Language Skills for Export Businesses; and Digital Humanities (LNU/FKH1).

During the years in focus here, developing an overall strategy for the Faculty of Arts and Humanities was an ongoing and partly autonomous process. It consisted of an attempt to formulate a strong and sustainable response to the process of development of a general university strategy. A "strategic plan" was established by the Faculty Board in 2014, placing research in the wider frame of all activities at the faculty, emphasising several components, one of which was "promoting highly valued publication in both scientific and artistic research" (LNU/FKH6, 3). In 2017, the faculty formulated three goals for research that are the result of a process spanning several years and relating to the university strategy:

1. research should be a main objective for all departments, relating to strong educational programs,

2. based on their own prerequisites each department or subject area should build national, leading research environments, and

3. research should be a force in external collaboration and critical analysis of the surrounding society, "from the universe to the county, from the beginning of time till now" (LNU/FKH4, 1).

Even if there is an emphasis on high impact publication output, the main focus is on building research environments, characterised by cross-disciplinarity and external collaboration. Issues focusing on publishing are primarily founded on formal decisions taken by the university Vice-Chancellor and subsequently implemented by the university library (LNU1, LNU3, LNU4). These decisions concern avenues of making research publicly available in a general sense. The model used for bibliometric evaluation has been formulated primarily in a series of guidelines on publication policy. However, the consequent actions to be taken are very much left to the individual researcher or research group to consider.

\subsubsection{University publication policy}

Linnaeus University has produced several policy documents on research publication practice, registration of published research, and the use of bibliometrics for internal distribution of university's research funding. Every year since 2013 a formal decision has been taken by the vice chancellor at the university on how the distribution of research funding should be implemented. Since 2013, $2.5 \%$ of the research funding has been distributed based on a bibliometric model. Until the vice chancellor's decision in 2018 the calculations and the distribution of research funding were made per individual researcher. The overall purpose of the local bibliometric evaluation is to stimulate increased publishing in channels with high scholarly/scientific prestige and good international dissemination (LNU4). Of the university's allocated state research funding, $5.1 \%$ is set aside for strategic purposes. The remaining funds are distributed to the faculties based on the distribution of the last fiscal year; $2.5 \%$ are reallocated based on bibliometrics and $2.5 \%$ on the amount of attracted external funding (LNU5).

Researchers active at the university are obliged to self-register their published scholarly material in the university's institutional repository DiVA (LNU1). Data extracted from DiVA are submitted to bibliometric evaluation according to locally decided criteria (LNU4). The value of this extraction thus depends on engagement by the individual researchers at the university. Evaluation is based on 
publications over a five-year period; thus, for the fiscal year of 2020, the evaluation is carried out in 2019 and is based on registered publications in DiVA with the publishing years 2014-2018. The evaluation is carried out based on a modified version of the Norwegian national bibliometric model described below (LNU4). According to Hammarfelt et al. (2016), several Swedish universities use the Norwegian model in different ways for distributing research funding. At Linnaeus University, this is done partly as a way to meet criticism from the humanities and social sciences disciplines that bibliometric evaluation generally has too narrow a focus on ranked, peer reviewed publications (LNU/FKH2). This focus is in line with the Swedish national model for research allocation introduced in 2010, which favours peer reviewed publications and is based on the amount of publications and citations in WoS as well as the amount of external funding; as proposed by the Swedish government in 2008 (Utbildningsdepartementet, 2008).

In the Norwegian model, publications score points based on publication type and the ascribed level (0-2) of the publication channel in the Norwegian Register for Scientific Journals, Series and Publishers (https://dbh.nsd.uib.no/publiseringskanaler), managed by the Norwegian Centre for Research Data (NSD). The three levels are as follows (Universitets- og høgskolerådet, 2004):

Level 0: The lowest rating. The publication channel has been assessed by NSD and is considered nonacademic. Scores no points in the model.

Level 1: The publication channel has procedures for external peer review, an academic editorial board and an international or national authorship.

Level 2: In addition to the criteria for level 1, publication channels at level 2 are considered the most leading, publishing the most significant publications by researchers from different countries. The publication channels at level 2 are the top $20 \%$ of the channels within an academic field. They are chosen based on a ranking made in accordance with Journal Impact Factor (JIF), where the citation frequencies in the different academic fields are considered. At Linnaeus University, the scores are calculated as seen in Table 1.

\begin{tabular}{|l|l|l|}
\hline Publication type & Level 1 score & Level 2 score \\
\hline Article & 1 & 3 \\
\hline Monograph & 5 & 8 \\
\hline Chapter in edited volume & 0.7 & 1 \\
\hline Conference paper & 0.7 & 1 \\
\hline
\end{tabular}

Table 1. Scores calculated at Linnaeus University

The Norwegian registry of publication channels has been locally extended also to include publication channels that are in WoS but left out of the Norwegian registry. Publication channels only in WoS are calculated as Norwegian level 1. Records with the DiVA content types "Refereed" or "Other academic" are included in the evaluation and compared against the extended registry, while records with the content type "Other (popular science, discussion, etc.)" are excluded.

The basis for the distribution of local research funds is made up by scores for the respective faculties within the last five-year period, where the score of one publication is fractionated by its number of authors (more than ten authors still count as ten) (LNU4) and is then normalized according to 
benchmark values to adjust the scores between the faculties (LNU3). The following benchmark values are used:

Benchmark value: 0.93

Department of Health and Caring Sciences (FHL)

Department of Medicine and Optometry (FHL)

Benchmark value: 1

Faculty of Technology (FTK)

Department of Biology and Environmental Science (FHL)

Department of Chemistry and Biomedical Sciences (FHL)

Benchmark value: 1.38

Faculty of Arts and Humanities (FKH)

Faculty of Social Sciences (FSV)

School of Business and Economics (FEH)

Department of Psychology (FHL)

Section for Higher Education Development (UB)

These values, current since 2016, are the medians of the publication score for researchers at the following Swedish universities: Karlstad University, Linköping University, Linnaeus University, Mid Sweden University, Stockholm University, Umeå University, Uppsala University, and Örebro University. The above-mentioned faculties and departments have been assigned one of the benchmark values based on the National Subject Category (Statistics Sweden, 2016) of the majority of its publications in the institutional repository (LNU4). The Faculty of Health and Life Sciences has been divided into its departments to be assigned separate values.

In the remainder of the text the term "Norwegian model" is used to refer to Linnaeus University's local application of the model, unless stated otherwise.

\section{Data collection and method of analysis}

The data collected for the present study consist of 3,316 metadata records of publications by authors affiliated with the Faculty of Arts and Humanities, self-registered by these authors during the period of 2010-2018. These were downloaded from the institutional repository DiVA (Inu.diva-portal.org) on the 10th of December 2019 upon retrieval using a set of search strings (see Appendix 2).

Individual records in the repository are registered by the researcher(s) and double-checked by an assigned librarian at the university library before being marked as approved in the repository. Upon approval, the records become part of the Swedish National Repository (SwePub) which is administered by the National Library of Sweden.

For each metadata record the following fields were extracted from the 15 categories native to DiVA describing publication type: (a) journal article, (b) article, research review, (c) article, book review, (d) monograph, (e) doctoral dissertation, monograph, (f) doctoral dissertation, compilation, (g) chapter in edited volume, (h) conference contribution, (i) licentiate thesis, monograph, (j) licentiate thesis, compilation, (k) editorial, proceedings, (I) artistic output, (m) report, ( $\mathrm{n}$ ) editorial, book, (o) miscellaneous. The miscellaneous category consists of entries that do not apply to any of the other publication categories in DiVA, such as research blog entries or project websites. 
In order to highlight the relation to institutional requirements in evaluation practice, the analysis emphasised peer-reviewed publications, that is, records from publication types (a), (d), (g), (h). The dataset was imported into the statistical tool JMP, and the network visualisations were created using the tool Cytoscape.

\section{Results}

Table 2 below shows the distribution of the number of publications per year. Comparing 2010 and 2018 , there is a $96.67 \%$ difference, with a continuous growth each of the included years. This is mainly due to increased research activity, as the total number of scholars producing research has been essentially stable during the entire period studied. One factor that might influence the level of registered records is the nature of the registration procedure as such. Two separate developments external to the library's routines must be considered. The university library aligns its repository services to (1) development of SwePub by the National Library of Sweden, for example by revising the deposit guidelines, and (2) the implementation of economic incentives based on bibliometric analysis, as formulated by the university management (LNU3 and LNU4). None of these factors should, however, be overestimated as researchers themselves are responsible for registration of their research output in the repository.

\begin{tabular}{|c|c|c|}
\hline Publication year & Number of records & Percent \\
\hline 2010 & 240 & 7.24 \\
\hline 2011 & 249 & 7.51 \\
\hline 2012 & 284 & 8.56 \\
\hline 2013 & 370 & 11.16 \\
\hline 2014 & 351 & 10.59 \\
\hline 2015 & 481 & 14.51 \\
\hline 2016 & 411 & 12.39 \\
\hline 2017 & 458 & 13.18 \\
\hline 2018 & 472 & 14.23 \\
\hline Total & 3316 & 100 \\
\hline
\end{tabular}

Table 2. Total records per year $(n=3316)$ 


\subsection{Preferred publication types}

The 15 publication types defined by DiVA consist of a large variety of different types of output, ranging from high-impact scholarly journals to popular science books and artistic works. The output grading made by the university prioritises and encourages peer-reviewed scholarly publications over the whole university without fully considering conditions or traditional publication practices within specific disciplines. Scholarly publications are awarded a score based on the modified Norwegian model (see above, 2.3.2.), while popular science and miscellaneous materials such as, for instance, research blogs are automatically awarded the score of zero.

Figure 1 demonstrates the distribution of publication types in the dataset. It is worth noting that there is a strong concentration of Level 0 DiVA records across the various types of publications. One distinguished feature is the almost complete absence of level 1 and 2 conference publications, with as many as $97.32 \%$ of conference publications being unaccounted for in the university's quality assessment process. Records related to conference publications count for $19.15 \%$ of the total sample. Even if the distribution between conference publications is clear enough, the figure must be put in relation to the character of the conference publication category as such, housing full paper contributions along with PowerPoint presentations, short or extended abstracts of presentations as well as a broad definition of what a "conference" is. In the material, no further distinction is made between for instance professional conferences, public fairs (such as book fairs), or full-scale scholarly conferences, other than that which is done by the individual scholar during the registration process.

Included in the evaluation is only the DiVA publication type "Conference contribution" with the subcategory "Published paper". The papers score points if they are of DiVA content type "Refereed" or "Other academic" and have been published in a channel with level 1 or 2 in the Norwegian model. There is a risk of arbitrariness here to be accounted for. While in many fields of research, such as computer sciences and mathematics, scientific conference publications are traditionally considered important, it is clear that humanist scholars do not see this form of knowledge sharing as a very significant outlet for research publication. The relatively high occurrence of conferences in the total sample does, however, indicate that conferences are used as a means to reach beyond the academic sphere. We interpret this as conferences being a major science communication arena, used to reach popular audiences. Therefore, this could be indicated as a major outlet, meeting managerial demands of societal outreach and public knowledge sharing. 


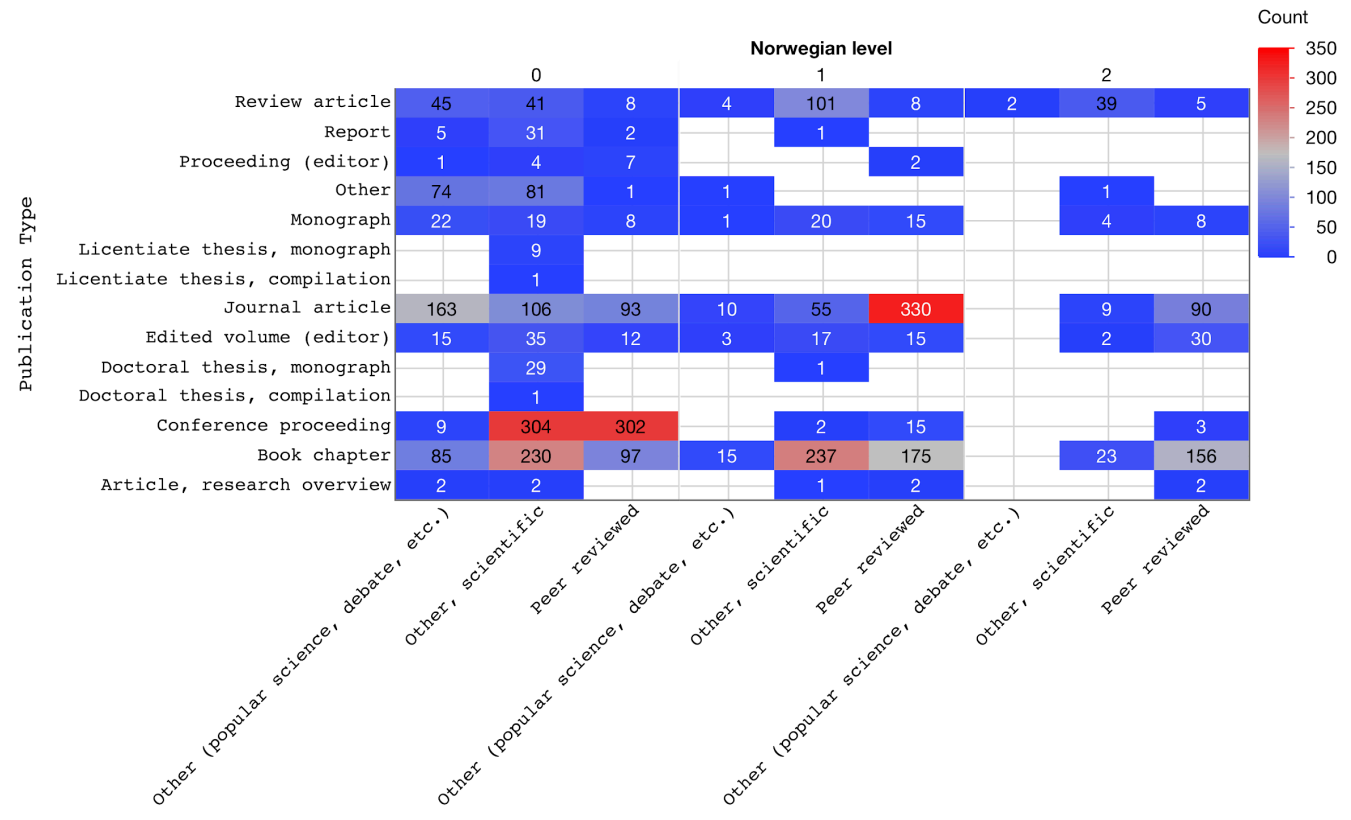

Content type

Figure 1: Distribution of DiVA records by publication type $(n=3,316)$

\subsubsection{Peer-reviewed publications}

As the bibliometric model implemented at Linnaeus University prioritizes publishing in peerreviewed, WoS-indexed materials, it is of value to analyse how the placement of such publication rates change over time, not least because of the significant increase in the total number of publications during the studied period. As seen in Figure 1 above, the relative occurrence of peerreviewed materials at levels 1 and 2 is concentrated in three publication categories: journal articles, monographs, and book chapters.

Figure 2 below shows the development of the relation between the total sample and these three categories over the investigated period. The totality of retrieved DiVA records reveals significant stability in the relation between peer-reviewed materials ranked by the Norwegian model and other, non-ranked materials. The total number of peer reviewed articles, monographs, chapters reach $29.31 \%$ over all nine years. Within the peer-reviewed material in Figure 2, the three main categories distribute as follows $(n=972)$ :

Journal articles: $52.78 \%(n=513)$

Book chapters: $44.03 \%(n=428)$

Monographs: $3.19 \%(n=31)$ 


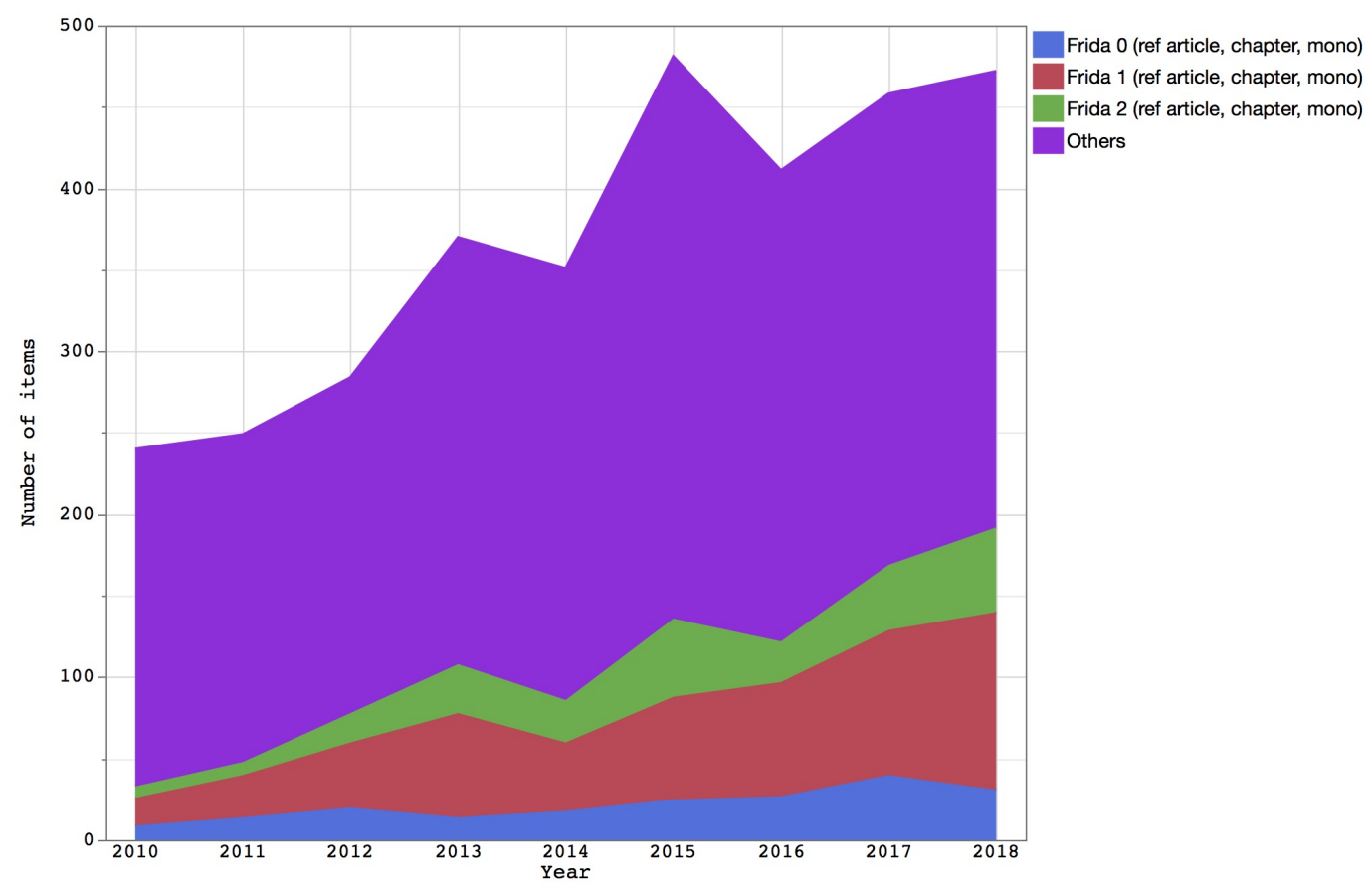

Figure 2: Journal articles, monographs and book chapters ranked in the Norwegian model in relation to total publication output over time $(n=3316)$.

Given that university management has over the studied period ascribed increased significance to bibliometric measures by connecting publication performance to individual benefits, such as increased internal research funding, it would make sense to observe a steady increase in peerreviewed publications by the scholars. However, although the data do indeed indicate a slight increase, it is of such limited magnitude that it is difficult to draw any conclusions regarding the success of managerial incentives and policies on practical research.

Comparing ranked publications in 2010 with those of 2018, there is a slight development, with the main increase to be found at level 1 publications within the Norwegian model. Level 1 journal articles, monographs and book chapters increased from $51.52 \%$ in 2010 to $56.77 \%$ in 2018. The figures for top tier, level 2 publications in 2010 were $21.21 \%$, compared to $27.08 \%$ in 2018. At the same time, the peer-reviewed journals, monographs, and book chapters at level 0 have decreased. This small but discernible movement may be caused by several reasons, such as increased scholars' awareness of the significance of publication choices, or the increased number of journals and book publishers within the humanities that during the studied years have been ranked within the Norwegian model.

\subsection{Disciplinary specificity}

Considering the incentives on developing cross-disciplinary centres and initiatives such as Anthropocene: Transdisciplinary Perspectives on Sustainable Development, one could expect an increased disciplinary overlap in publications. The results show that this was not the case. When clustering publication practices by any of the 31 individual subject areas at the faculty, national subject categories and the locally defined subject categories are mostly overlapping, creating a picture of the faculty division well within the realm of traditional disciplinary boundaries (Golub et al., 2020). In the somewhat larger dataset for this current study, this comes through clearly as well. Figure 3 below shows the distribution of peer-reviewed journal articles, monographs, and book chapters 
between the 31 disciplines of the Faculty of Arts and Humanities at Linnaeus University, with the 6 largest disciplines highlighted:

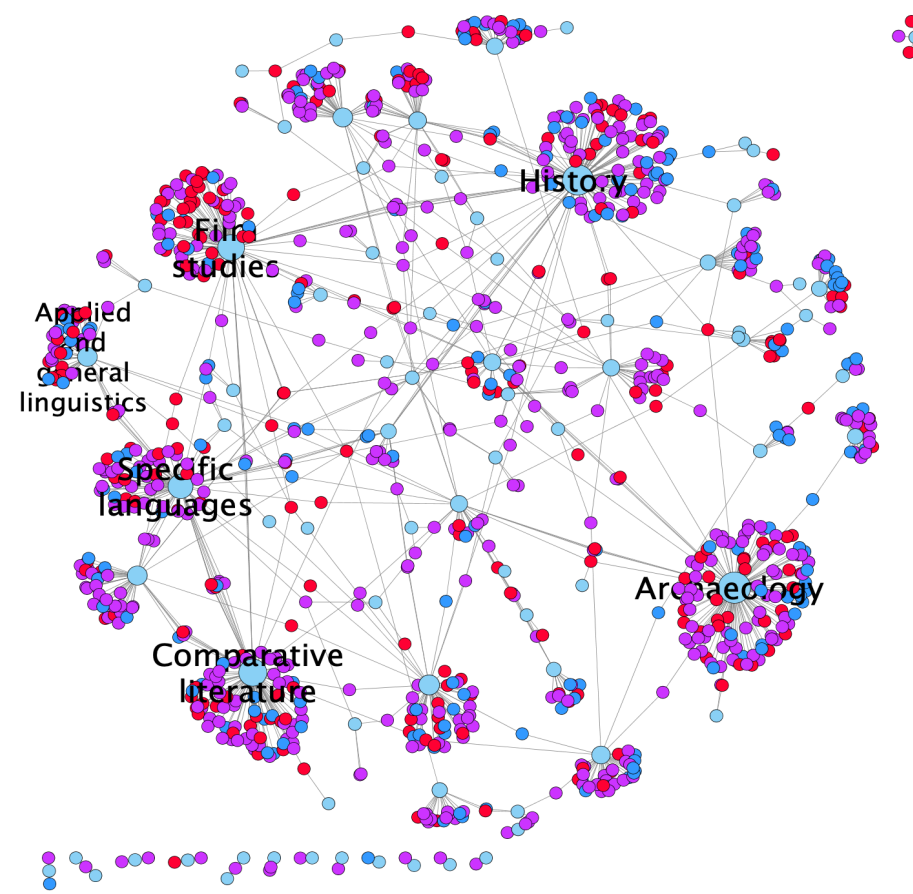

Figure 3: Distribution of peer-reviewed publications (journal articles, monographs, book chapters) ranked by the Norwegian model ( $n=972$ ). Blue: level 0, Purple: level 1, Red: level 2.

In terms of general publication rates, the six largest are nationally well-established disciplines (Comparative Literature, Specific Languages, Applied and General Linguistics, Film Studies, History and Archaeology); at the same time, they are the most coherent ones in terms of level 2 concentration. The general distribution of ranked publications at all three levels is shown in the relative dominance of level 2 publications in all major disciplines of the faculty. The highlighted disciplines either have a strong international publication structure, such as Archaeology, History, and Applied and General Linguistics, or a strong cross-disciplinary reach through, for instance, established interdisciplinary centres like Linnaeus University Centre for Intermedial and Multimodal Studies, where fields like Comparative Literature and Film Studies are prominent. Perhaps the most surprising finding here is the concentration of level 2 publications in Film Studies, a discipline with only a few active scholars at the University. This may be down to several factors such as highly productive, internationally recognised individuals, frequent publication in a limited number of established scholarly journals within the field, or publications in cross-disciplinary journals and anthologies with individual contributions indexed as Film Studies. However, in order to establish these factors for certain, and the relation between them, a more qualitative approach would need to be applied.

Beside the "Big Six" at the faculty, in terms of publications, the remaining 26 disciplines display a majority of level 1 publications and numerous connections into various parts of the main research areas. This picture corresponds well with established knowledge on the vagueness of many disciplines within the humanities, and several nodes in the graph most likely reflect the output of individual scholars whose publications fall in-between established subject categories. The network character of cross-disciplinary publications could be attributed to the oft-claimed vagueness of humanities disciplines, but the pattern displayed may also indicate a high degree of co-operation and cross- 
disciplinary collaboration. In all, these results are indicative of the complex relation between bibliographic systems and scholarly practice, and they call for further qualitative in-depth research.

\subsection{Level of co-authorship}

One of the most common assertions about humanities scholars is their affinity for solitary work. In recent literature on the transformation of traditional humanities practices into digital humanities, the image of the lone scholar in their ivory tower is often portrayed as antiquated, particularly in relation to the more collaborative character promoted as an ideal in digital humanities settings (Siemens, 2009). However, cliché-based assertions such as these are rarely useful for enhancing our understanding of the value of humanities research, neither in the historical nor the contemporary perspective; indeed, as pointed out by Burroughs, there are significant differences between departments including many that contest a "monolithic view" of the humanities (2017, p. 516). Still, practices can change over time, and collaborative efforts are hailed from managerial perspectives as a means to address 'societal challenges', which, not least in Sweden, have come to assume a position of particular importance when it comes to setting objectives for scholarly inquiry. Given that Linnaeus University has, during the period in focus here, promoted such collaborative ideals by providing economic incentives, it is reasonable to expect that future research output will show an increase in collaborative research. The dataset used, however, shows a stable structure over the whole period with only minimal differences for each year and traces of both incentives and scholarly discourse are mostly absent, instead supporting the image of the lone scholar as a still dominant figure in humanities research. Figure 4 shows the collected number of authors in the total number of records:

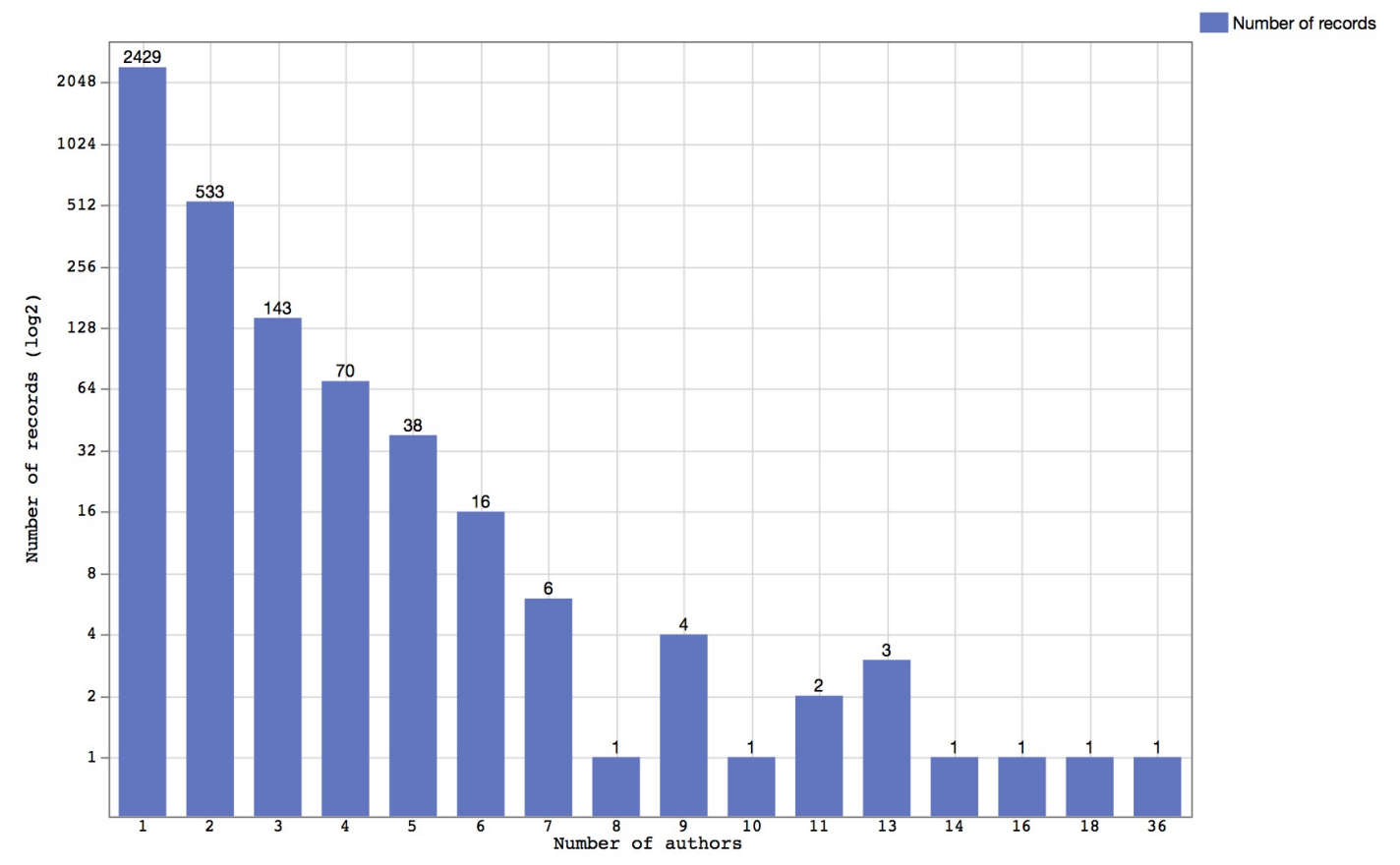

Figure 4: Number of authors in total number of records ( $n=3316)$; vertical axis expressed on a logarithmic scale

The data set reveals a strong emphasis on single-authored publication. In all, $73.25 \%$ of the total number of records are attributed to only one author; $26.07 \%$ have two authors, and a mere $8.69 \%$ 
have three or more authors attributed. This is consistent with other studies such as Tang et al. (2017), indicating that the established practices of co-authorship in the humanities govern working practices in disciplines across the dataset. This suggests that managerial incentives may not have succeeded in emphasizing the value of collaboration and co-authorship as such, and a reason for this could be that the Norwegian model allocates less points for publications with multiple authors due to author fractionation. This result indicates that policy promoting collaboration and cross-disciplinary initiatives comes in direct conflict with research practice.

\subsection{Preferred publication language}

As the bibliometric model used by the University during the studied period follows not only the Norwegian list of indexed journals and publishers, but also complements the list with additional journals indexed in WoS, the incentive to publish internationally in English is further emphasised through university policy (LNU4). It is therefore interesting to look at the choice of publication language, particularly in light of the long tradition in the humanities of publishing in national languages. Given the adherence to traditional humanistic practices we have been able to show so far, it would be reasonable to expect that the analysis of the language of publication would reveal a substantial number of registered publications in Swedish, and other non-English languages. However, the results meet such expectations only to a certain degree. A language break-down of the complete set $(n=3316)$ proves the following presence of languages:

English: $53.05 \%(n=1759)$

Swedish: $39.51 \%(n=1310)$

Others: $7.45 \%(n=247)$

Breaking out ranked peer-reviewed publications only, the picture develops even further $(n=1386)$ :

English: $80.16 \%(n=1111)$

Swedish: $13.06 \%(n=181)$

Others: $6.78 \%(n=94)$

When distinguishing the three main categories within the peer-reviewed category - journal articles, monographs, and book chapters - the distribution of languages holds for all three, although with slight relative differences; monographs and book chapters show in the total set a higher representation of publications in Swedish with $53.61 \%$ and $47.54 \%$ respectively. Although within the peer-review category, both show a strong dominance of publications written in English, with $61.29 \%$ for monographs, and $\mathbf{7 3 . 8 3 \%}$ for book chapters. For journal articles, the dominance of English is strong, with most published items regardless of peer-review or ranking published in English. When we consider the total amount of journal articles, 59.98\% were written in English, while in the ranked, peer-reviewed category, $82.65 \%$ of the registered articles were written in English.

\section{Concluding remarks}

Breaking traditional practices of scholarly disciplines is notoriously difficult. Traditional preferences run deep, and of course one may argue that there is a reason for this. The expected deliverables of research in disciplines within the broad framework of the humanities differ from that of the sciences. Technological, managerial, economic, and societal challenges demand new approaches from disciplines across the line, and with the emergence of new methodological tools and routes for knowledge dissemination, old traditions need to be analysed, and practices of publication and knowledge dissemination discussed. This study contributes to such discussion by displaying 
publication practices at a young, regional university in a country known for its high standards of learning and industrious innovation.

The picture that emerges in this study confirms the power of tradition in humanities publication practices. Despite continuous performance-based funding incentives that direct research output to international peer-reviewed, top-tier channels, the use and variety of other kinds of publication types remains substantial. However, as Sille and Vanderstraeten point out in their study of educational research, results are bound to be inconclusive concerning influencing factors due to the difficulties of isolating certain incentives as more influential on practice than others (2019). This is particularly valid when studying the humanities (Hammarfelt, 2016; Narayan et al., 2018). Also, in line with traditional apprehensions of the humanities is the limited amount of co-authorship in the registered publications. The development towards a higher degree of co-authorship, often regarded as a characteristic feature of digital humanities research (Siemens, 2009; Siemens et al., 2011), has yet to take root in research practice.

Only in terms of language choice, which as noted varies between disciplines, does the data indicate a shift from what is generally assumed to be a native language tradition in the humanities. English comes forth as the overall most used language, both in the total sample, and most particularly in the peer-reviewed publications accounted for in the Norwegian model. The dominant role of English as the prime language of publications registered in the local repository is noteworthy. It seems reasonable to attribute this to the increasingly international research environment established during the studied timeframe in cross-disciplinary research centres of the Faculty of Arts and Humanities, which are predominantly made up of the "big six" disciplines as seen in Figure 3.

Overall, the results are well in line with the findings of Guns et al. (2019) on social science and humanities research practices. Perhaps the most important difference is that while Guns et al. noticed a decline in non-peer-reviewed publications over time, no such trend is seen in the dataset of this study. Part of the explanation may lie in the inclusion of social science in their study, whilst in this study, we define the humanities in a more exclusive manner.

The results of this case study raise questions about the effectiveness of managerial incentives to direct publication patterns into a form that is not discipline specific, even if it is combined with a vectored bibliometric practice that is seen here in the form of the Norwegian model, which is used at Linnaeus University as well as at several other Swedish universities. Although vague, the indication is that changing impetus within actual research practice influences developments in a more significant way as follows. Although it is difficult to substantiate with certainty, the development of cross-disciplinary centres of research has likely impacted preferred languages in all major disciplines in the dataset, as they tend to be oriented towards international research environments. From this perspective, the present study suggests that if management incentives are to influence research practice, they ought to focus on the development of self-organizing research communities based on reformulation of both research missions and actual problem statements, relating to current societal challenges. In that way, the specific ways of relating to the world that have for long been the hallmark of the humanities can be taken advantage of, in the quest to keep universities continuously relevant in present and future societal developments.

Furthermore, the findings raise new questions and motivate follow-up studies in at least two areas: 1 ) in depth studies of publication patterns inside strategic cross-disciplinary research centres and initiatives to see if they differ from the more established patterns of participating disciplines; and, 2) the influence of digital humanities discourse and practice on humanities publication patterns in local 
university environments. An examination of the results of the present study in light of in-depth followups studies within these two areas would benefit not only local strategic thinking in universities promoting humanities research, but the international discussion on the social value of the humanities at large.

\section{Acknowledgements}

The authors would like to thank Dr. Fredrik Åström at Lund University for his helpful reading of an early version of this article. They would also like to thank the anonymous reviewers assigned by NJLIS for their constructive comments. 


\section{References}

Aagaard, K. (2015). How incentives trickle down: Local use of a national bibliometric indicator system. Science and Public Policy, 45(5), 725-737. http://doi.org/10.1093/scipol/scu087

Ahlgren, P., Colliander, C., \& Persson, O. (2012). Field normalized rates, filed normalized journal impact and Norwegian weights for allocation of university funds. Scientometrics, 92(3), 767-780. https://doi.org/10.1007/s11192-012-0632-x

Borgman, C. (2007). Scholarship in the digital age: information, infrastructure, and the Internet. MIT Press.

Budd, J. M., \& Dumas, C. (2014). Epistemic multiplicity in iSchools: Expanding knowledge through interdisciplinarity / La multiplicité épistémique dans les iSchools: le développement des connaissances grâce à l'interdisciplinarité. Canadian Journal of Library and Information Science, 38(4), 276-286. https://doi.org/10.1353/ils.2014.0020

Bunia, R. (2016). Quotation statistics and culture in literature and in other humanist disciplines: What citation indices measure. In M. Ochsner, S. E. Hug, \& H.-D. Daniel (Eds.), Research assessment in the humanities: towards criteria and procedures (pp. 133-148). Springer.

https://doi.org/10.1007/978-3-319-29016-4_11

Burroughs, J. M. (2017). No uniform culture: Patterns of collaborative research in the humanities. Portal: Libraries and the Academy, 17(3), 507-527. https://doi.org/10.1353/pla.2017.0032

Carlsson, H., Kettis, Å., \& Söderholm, A. (2014). Research quality and the role of university leadership. The Association of Higher Swedish Education.

https://suhf.se/app/uploads/2019/07/Expertgruppen-kvalitet-2010-2011-Bilaga-4-ResearchQuality-and-the-Role-of-the-University-Leadership.pdf

De Silva, P. U. K., \& Vance, C. K. (2017). Scientific scholarly communication: the changing landscape. Springer. https://doi.org/10.1007/978-3-319-50627-2

de Solla Price, D. J. (1963). Little Science, Big Science. Columbia University Press.

de Solla Price, D. J. (1965). Networks of scientific papers. Science, 149(3683), 510-515.

https://doi.org/10.1126/science.149.3683.510

East, J. W. (2007). Subject retrieval from full-text databases in the humanities. Portal: libraries and the academy, 7(2), 227-241. http://doi.org/10.1353/pla.2007.0018

European Science Foundation. (2014, July 9). European Reference Index of the Humanities (ERIH). http://archives.esf.org/hosting-experts/scientific-review-groups/humanities-hum/erih-europeanreference-index-for-the-humanities.html

Franssen, T., \& Wouters, P. (2019). Science and its significant other: Representing the humanities in bibliometric scholarship. Journal of the Association for Information Science and Technology, 70(10), 1124-1137. https://doi.org/10.1002/asi.24206

Golub, K., Tyrkkö, J., Hansson, J. \& Ahlström, I. (2020). Subject indexing in humanities: A comparison between a local university repository and an international bibliographic service. Journal of Documentation, 76(6), 1193-1214. https://doi.org/10.1108/JD-12-2019-0231 
Guns, R., Eykens, J., \& Engels, T. C. E. (2019). To what extent do successive cohorts adopt different publication patterns? Peer review, language use and publication types in the social sciences and humanities. Frontiers in Research Metrics and Analytics, 3, Article 38. https://doi.org/10.3389/frma.2018.00038

Hammarfelt, B., \& de Rijcke, S. (2015). Accountability in context: Effects of research evaluation systems on publication practices, disciplinary norms, and individual working routines in the faculty of Arts at Uppsala University. Research Evaluation, 24(1), 63-77. https://doi.org/10.1093/reseval/rvu029

Hammarfelt, B., Nelhans, G., Eklund, P., \& Åström, F. (2016). The heterogeneous landscape of bibliometric indicators: Evaluating models for allocating resources at Swedish universities. Research Evaluation, 25(3), 292-305. https://doi.org/10.1093/reseval/rvv040

Hammarfelt, B. (2016). Beyond coverage: towards a bibliometrics for the humanities. In M. Ochsner, S. E. Hug, \& H.-D. Daniel (Eds.), Research assessment in the humanities: towards criteria and procedures (pp. 115-131). Springer. https://doi.org/10.1007/978-3-319-29016-4_10

Kennerly, M., Frederick, S., \& Abel, J. E. (Eds.). (2021). Information: Keywords. Columbia University Press.

Narayan, B., Luca, E. J., Tiffen, B., England, A., Booth, M., \& Boateng, H. (2018). Scholarly communication practices in humanities and social sciences: a study of researchers' attitudes and awareness of Open Access. Open Information Science, 2(1), 168-180. https://doi.org/10.1515/opis2018-0013

Schneider, J. W. (2009). An outline of the bibliometric indicator used for performance-based funding of research institutions in Norway. European Political Science, 8(3), 364-378.

https://doi.org/10.1057/eps.2009.19

Siemens, L. (2009). 'It's a team if you use "reply all"': An exploration of research teams in digital humanities environments. Literary and Linguistics Computing, 24(2), 225-233.

https://doi.org/10.1093/llc/fqp009

Siemens, L., Cunningham, R., Duff, W., \& Warwick, C. (2011). A tale of two cities: Implication of the similarities and differences in collaborative approaches within digital libraries and digital humanities communities. Literary and Linguistics Computing, 26(3), 335-348.

https://doi.org/10.1093/llc/fqr028

Sïle, L., \& Vanderstraeten, R. (2019). Measuring changes in publication patterns in a context of performance-based research funding systems: The case of educational research in the University of Gothenburg (2005-2014). Scientometrics, 118(1), 71-91. https://doi.org/10.1007/s11192-018-29638

Snow, C. P. (1959). The two cultures and the scientific revolution. Cambridge University Press.

Statistics Sweden. (2016). Standard för svensk indelning av forskningsämnen 2011; uppdaterad augusti 2016. Statistiska Centralbyrån.

https://www.scb.se/contentassets/10054f2ef27c437884e8cde0d38b9cc4/standard-for-svenskindelning--av-forskningsamnen-2011-uppdaterad-aug-2016.pdf 
Tang, M. C., Cheng, Y. J., \& Chen, K. H. (2017). A longitudinal study of intellectual cohesion in digital humanities using bibliometric analyses. Scientometrics, 113, 985-1008.

https://doi.org/10.1007/s11192-017-2496-6

Tibbo, H. R. (1994). Indexing for the humanities. Journal of the American Society for Information Science, 45(8), 607-619. https://doi.org/10.1002/(SICI)1097-4571(199409)45:8\%3C607::AIDASI16\%3E3.0.CO;2-X

Universitets- og høgskolerådet. (2004). Vekt på forskning: Nytt system for dokumentasjon av vitenskapelig publisering: Innstilling fra faglig og teknisk utvalg til UHR. Universitets- og høgskolerådet. https://npi.nsd.no/informasjon\#vektpa

Utbildningsdepartementet. (2008). Ett lyft för forskning och innovation (Regeringens proposition 2008/09:50). Regeringskansliet. https://data.riksdagen.se/fil/F4F66159-F5A7-424E-9E60-

$4 \mathrm{AF} 83790 \mathrm{C} 165$ 


\section{Appendix 1: White Papers and Guidelines, Linnaeus University}

LNU1. Riktlinjer för elektronisk publicering vid Linnéuniversitetet. [Guidelines for Electronic Publishing at Linnaeus University.] Decided on 2011-10-24. Kalmar/Växjö: Linnaeus Univ. https://Inu.se/globalassets/dokument---gemensamma/bibliotek/publicera-idiva/riktlinjer_epublicering.pdf

LNU2. En resa in i framtiden: Vision och strategi 2015-2020. [A Journey into the Future: Vision and Strategy 2015-2020.] https://Inu.se/globalassets/dokument--gemensamma/universitetsledningens-kansli/en_resa_in_i_framtiden_2015-2020.pdf

LNU3. Beslut om intern fördelning av forskningsanslag 2020. [Decision on Internal Distribution of Research Allocation 2020.] Dnr: 2019/2478-1.1.3. Kalmar/Växjö: Linnaeus Univ.

LNU4. Bibliometrisk modell för vetenskapliga publikationer vid Linnéuniversitetet. Bilaga till beslut om fastställande av Linnéuniversitetets bibliometriska modell för vetenskapliga publikationer. [Bibliometric Model for Scholarly Publications at Linnaeus University. Appendix to Decision on Approval of Linnaeus University's Bibliometric Model for Scholarly Publications.] Dnr: 2019/10811.1.1. Kalmar/Växjö: Linnaeus Univ.

LNU5. Verksamhetsplan och budget 2020-2022. [Operational Plan and Budget 2020-2022.] Dnr: 2019/3656-1.1.1. Kalmar/Växjö: Linnaeus Univ. https://Inu.se/globalassets/dokument--gemensamma/universitetsledningens-kansli/verksamhetsplanering/galler-vp-och-budget-20202022_w.pdf

LNU/FKH1. En utvecklande forskningsstrategi: Självvärdering för Fakulteten för konst och humaniora. [A Developing Research Strategy: Self Evaluation for the Faculty of Arts and Humanities.]

LNU/FKH2. Kvalitetsarbete forskning vid fakulteten för konst och humaniora. [Quality Management, Research at the Faculty of Arts and Humanities.] (2019-10-02)

LNU/FKH3. Arbetet med En utvecklande forskningsstrategi inom Fakulteten för konst och humaniora vid Linnéuniversitetet. [Working with A Developing Research Strategy within the Faculty of Arts and Humanities at Linnaeus University.] (2017-03-01)

LNU/FKH4 (2017) Inspel till forskningsstrategi vid fakulteten för konst och humaniora. [Input to Research Strategy at the Faculty of Arts and Humanities.] (2017-03-01)

LNU/FKH5. Slutrapport från utredningen av forskarutbildningen vid fakulteten för konst och humaniora (FKH). [Final Report from the Inquiry of the Postgraduate Education at the Faculty of Arts and Humanities.] (2014-09-05)

LNU/FKH6. Strategisk plan för fakulteten för konst och humaniora 2015-2020. [Strategic Plan for the Faculty of Arts and Humanities 2015-2020.] (2014-12-15)

LNU/FKH7. Strategi för digital humaniora 2019-2021. [Strategy for Digital Humanities 2019-2021.] Fakulteten för konst och humaniora, Missiv 2019-06-10. Dnr: 2018/1074-1.5. Kalmar/Växjö: Linnaeus Univ. 


\section{Appendix 2: Search strings in data collection}

Publishing year: $2010-2018$

AND

Organisation(id): Faculty of Arts and Humanities Include former name in search

OR

Organisation(id): School of Cultural Sciences (2012-12-31)

Include former name in search

OR

Organisation(id): School of Language and Literature (2012-12-31)

Include former name in search

NOT

Publication type:

Data set

Patent

Student thesis 
Appendix 3: Distribution of publication types in the complete data set $(n=3316)$

\begin{tabular}{|c|c|c|}
\hline Publication type & Number of records & Percent \\
\hline A. Article in journal & 856 & 25.81 \\
\hline B. Article, review/survey & 9 & 0,27 \\
\hline C. Article, book review & 253 & 7,63 \\
\hline D. Book & 97 & 2,93 \\
\hline $\begin{array}{l}\text { E. Doctoral thesis, } \\
\text { monograph }\end{array}$ & 31 & 0,93 \\
\hline $\begin{array}{l}\text { F. Doctoral thesis, } \\
\text { comprehensive } \\
\text { summary }\end{array}$ & 1 & 0,03 \\
\hline G. Chapter in book & 1018 & 30,70 \\
\hline H. Conference paper & 635 & 19,15 \\
\hline $\begin{array}{l}\text { I. Licentiate thesis, } \\
\text { monograph }\end{array}$ & 9 & 0,27 \\
\hline $\begin{array}{l}\text { J. Licentiate thesis, } \\
\text { comprehensive } \\
\text { summary }\end{array}$ & 1 & 0,03 \\
\hline $\begin{array}{ll}\text { K. } & \text { Conference } \\
& \text { proceedings (editor) }\end{array}$ & 14 & 0,42 \\
\hline L. Artistic output & 66 & 1,99 \\
\hline M. Report & 39 & 1,18 \\
\hline N. Collection (editor) & 129 & 3,89 \\
\hline O. Other & 158 & 4,76 \\
\hline
\end{tabular}

